\title{
Amyloid Precursor Protein in Cortical Neurons: Coexistence of Two Pools Differentially Distributed in Axons and Dendrites and Association with Cytoskeleton
}

\author{
Bernadette Allinquant, ${ }^{1}$ Kenneth L. Moya, ${ }^{2}$ Colette Bouillot, ${ }^{1}$ and Alain Prochiantz ${ }^{1}$ \\ 'CNRS URA 1414, Ecole Normale Supérieure, 75230 Paris Cedex 05, France, and ${ }^{2}$ CNRS URA 1285 and INSERM U334, \\ SHFJ-CEA, Orsay, France
}

\begin{abstract}
Embryonic cortical neurons in culture contain transmembrane amyloid precursor protein (APP) capable of associating with the detergent-insoluble cytoskeleton through interactions requiring the presence of its $\mathrm{C}$-terminal. These transmembrane APPs are not detectable at the surface of living cells. When neurons are fixed with paraformaldehyde alone, APP is mainly visualized close to the membrane of the axon and cell body of $40 \%$ of neurons, with virtually no dendritic staining. Membrane permeabilization with detergent or methanol extends APP immunostaining to $100 \%$ of the cells and to all compartments, including the dendrites. Taken together, these results suggest that APP in embryonic neurons Is present in two compartments, one more readily detectable in some axons and cell bodies and the other distributed throughout all neurons. The axonal and somatic pool of APP detectable after paraformaldehyde fixation alone is highly and rapidly augmented after exposure to calcium ionophores. We propose that calcium entry increases the amount of axonal APP close to the cell surface, but that the stabilization of the protein at the cell surface and its subsequent secretion require further physiological stimuli.
\end{abstract}

[Key words: amyloid precursor protein, neurons, primary culture, polarity, cytoskeleton, differentiation]

Extracellular senile plaques found in Alzheimer's disease and in Down's syndrome are characterized by fibrillary deposits containing the $\beta \mathrm{A} 4$ amyloid peptide. This peptide is a fragment cleaved from the amyloid precursor protein (APP), which is ubiquitously expressed in the nervous system from early embryogenesis throughout adulthood. APP is derived from a single gene, which by alternative splicing yields three principal isoforms designated APP770, APP751, and APP695. This latter isoform, APP695, lacks the Kunitz protease inhibitor domain observed in the other isoforms and is the major form in neurons (for review, see Selkoe, 1991). Sequence analysis of APP suggests an integral membrane protein with a long $\mathrm{N}$-terminal region, a transmembrane domain, and a short C-terminal tail (Kang et al., 1987).

Received Jan. 6, 1994; revised Apr. 1, 1994; accepted May 10, 1994.

We thank Dr. J. N. Octave for discussions and Dr. P. Denoulet for help in preparing microtubules. Dr. P. Frey generously contributed the APP C-terminal antibody and Dr. A. Fellous provided the antibodies against tau and MAP2. This work was supported by Centre National de la Recherche Scientifique, Ecole Normale Supérieure, Direction des Recherches et Etudes Techniques (DRET 92-141), and Institut National de la Santé et de la Recherche Médicale (CRE 930807).

Correspondence should be addressed to Dr. A. Prochiantz, CNRS URA 1414, Ecole Normale Supérieure, 46 rue d'Ulm, 75230 Paris Cedex 05, France.

Copyright (1994 Society for Neuroscience 0270-6474/94/146842-13\$05.00/0
APP is subject to a number of proteolytic events, some of which give rise to $\beta \mathrm{A} 4$-containing fragments with variable $\mathrm{C}$-termini observed in endosomes and lysosomes (Estus et al., 1992; Golde et al., 1992). Recent studies have reported the production and release of $\beta A 4$ itself(Haass et al., 1992; Seubert et al., 1992), but it is not yet clear if this involves a distinct processing pathway. In addition, APP is normally processed in a constitutive secretory pathway in which the long $\mathrm{N}$-terminal region is cleaved near the extracellular membrane surface within the $\beta \mathrm{A} 4 \mathrm{se}-$ quence and released (Palmert et al., 1989; Schubert et al., 1989; Weidemann et al., 1989; Esch et al., 1990; Sisodia et al., 1990; Sisodia, 1992). In the brain, all of these processes may act to different degrees to produce $\beta \mathrm{A} 4$ amyloid deposits. However, the specific cells in which APP metabolism is disrupted are unknown. One likely possibility are the neurons that contain considerable APP immunoreactivity in the vicinity of amyloid plaques (Martin et al., 1991).

The physiological role of APP has yet to be elucidated, but the relative abundance of APP 695 in neurons indicates a specific biological function, and some have suggested that the protein participates in cell-cell interactions. In peripheral nerve the protein is rapidly transported down the axons (Koo et al., 1990), and in a developing central pathway its synthesis and axonal transport coincide with axon elongation and synaptogenesis (Moya et al., 1994). In the mature nervous system, the protein has been localized to both peripheral and central synaptic sites (Schubert et al., 1991). Studies using neuronal cell lines have shown that APP can mediate cell-cell and cell-substrate adhesion (Schubert et al., 1989; Breen et al., 1991), and recently it has been suggested that APP may function as a G-proteincoupled receptor (Nishimoto et al., 1993). In addition, amyloid precursor protein expression increases during neuronal differentiation (Hung et al., 1992).

To begin to understand the biological function of APP, we studied the localization of the protein in differentiating primary neurons under normal and calcium-stimulated culture conditions. This led us to examine the localization of APP and its association with the cytoskeleton. We found that APP is distributed into two distinct intracellular pools, and we propose a model in which one of these pools, highly enriched in the axon, would cycle rapidly with the neuronal surface but would only be stabilized at the surface upon specific physiological stimuli.

\section{Materials and Methods}

Primary cell cultures. Cortical ncurons wcrc prepared from E15 or E16 rat fetuses as previously described (Lafont et al., 1992). Viable dissociated cells were plated onto polyornithine (Sigma; $1.5 \mu \mathrm{g} / \mathrm{ml}$ )-coated coverslips (at a density of $50 \times 10^{3} / \mathrm{cm}^{2}$ ) for immunolabeling experi- 
ments or onto polyornithine-coated plastic dishes (at a density of 15 $30 \times 10^{4} / \mathrm{cm}^{2}$ ) for biochemistry experiments. Neuronal cultures were incubated in a chemically defined medium (CDM) free of serum and supplemented with hormones, proteins, and salts.

Primary astrocyte cultures were prepared according to McCarthy and de Vellis (1980) from trypsinized neonatal rat cortices stripped of meninges. Dissociated viable cells were plated onto polylysine (Sigma; 1.5 $\mu \mathrm{g} / \mathrm{ml}$ )-coated plastic dishes at an initial density of $20 \times 10^{3} / \mathrm{cm}^{2}$ in Dulbecco's modified Eagle's medium (DMEM) with 10\% fetal calf serum, and cultured for $10 \mathrm{~d}$ before use.

Cell fractionation and homogenization. Neurons (10\%/dish) at $5 \mathrm{~d}$ in vitro (DIV) were rinsed twice in TBS pH $7.4(50 \mathrm{~mm}$ Tris- $\mathrm{HCl}, 150 \mathrm{~mm}$ $\mathrm{NaCl}, 5 \mathrm{~mm}$ EDTA), and scraped in $0.5 \mathrm{ml}$ of TBS with protease inhibitors ( $1 \mathrm{mM}$ Pefablock, $1 \mu \mathrm{M}$ leupeptin, $1 \mu \mathrm{M}$ pepstatin, and $0.3 \mu \mathrm{M}$ aprotinin). The cells were homogenized in a Dounce homogenizer, and centrifuged at $1000 \times g$ for $5 \mathrm{~min}$. The supernatant was then centrifuged at $100,000 \times g$ for $1 \mathrm{hr}$ at $4^{\circ} \mathrm{C}$ to yield a cytosolic fraction and a particulate pellet. In some experiments, the high-speed pellets containing membrane-associated proteins were resuspended in $0.1 \mathrm{M}$ sodium carbonate, pH 11.05, for $30 \mathrm{~min}$ at $4^{\circ} \mathrm{C}$ and centrifuged at $100,000 \times$ $g$ for $1 \mathrm{hr}$ at $4^{\circ} \mathrm{C}$. The pellets were then resuspended in TBS plus protease inhibitors and $0.5 \%$ Triton $\mathrm{X}-100$.

Cell surface biotinylation. Cells were washed three times in PBS pH 7.4 and incubated with sulfo-NHS-SS-biotin (Pierce Chemical) at 200 $\mu \mathrm{g} / \mathrm{ml}, 30 \mathrm{~min}$ at $4^{\circ} \mathrm{C}$ or $5 \mathrm{~min}$ at $37^{\circ} \mathrm{C}$. These conditions were determined to give access to membrane constituents without altering the viability of the cells, as determined by trypan blue exclusion. The cells were then washed once in PBS-glycine and twice in PBS, scraped from the dish, homogenized, and fractionated as described above. The particulate pellet was resuspended in PBS with 2\% SDS and boiled for $5 \mathrm{~min}$. After cooling, 4 vol of $50 \mathrm{~mm}$ Tris- $\mathrm{HCl} \mathrm{pH} 7.4,190 \mathrm{~mm} \mathrm{NaCl}, 6 \mathrm{~mm}$ EDTA, $2.5 \%$ Triton $\mathrm{X}-100$ was added to 1 vol of extract. The suspension was centrifuged at $4^{\circ} \mathrm{C}$ for $5 \mathrm{~min}$ at $7800 \times g$ and the supernatant mixed with avidin-agarose beads overnight at $4^{\circ} \mathrm{C}$. After five washes in $10 \mathrm{~mm}$ Tris- $\mathrm{HCl} \mathrm{pH} \mathrm{7.4,} 150 \mathrm{~mm} \mathrm{NaCl}, 5 \mathrm{~mm}$ EDTA, $0.05 \%$ SDS, $0.1 \%$ Triton $\mathrm{X}-100$ and one wash in $10 \mathrm{~mm}$ Tris- $\mathrm{HCl} \mathrm{pH} \mathrm{7.4,500} \mathrm{mM} \mathrm{NaCl,} 5 \mathrm{~mm}$ EDTA, biotinylated proteins were desorbed from avidin-agarose by boiling for $5 \mathrm{~min}$ in Laemmli sample buffer containing 5\% SDS.

Immunocytochemistry. Neurons were fixed with paraformaldehyde (4\% in PBS, pH 7.4) for 20 min at room temperature. After rinsing with PBS, nonspecific binding was blocked with $10 \%$ newborn calf serum (GIBCO) in PBS (PBS-serum) for $60 \mathrm{~min}$ at $37^{\circ} \mathrm{C}$, and the cells were

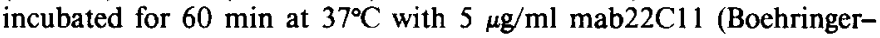
Mannheim) or with an anti-C-terminal serum (1:200) provided by Dr. Frey (Palacios et al., 1992). Coverslips were rinsed and APP immunoreactivity was visualized with Texas red-conjugated secondary antibody ( 45 min at $37^{\circ} \mathrm{C}$ ), or with a biotinylated secondary antibody $(45$ min at $37^{\circ} \mathrm{C}$ ) followed by Texas red-conjugated streptavidin $(20 \mathrm{~min}$ at $37^{\circ} \mathrm{C}$ ). All secondary antibodies and amplification reagents were from Amersham and all incubations and dilutions were in PBS serum. In some experiments, where indicated, the cells were permeabilized with $0.2 \%$ Triton X-100 after fixation and then treated as above in PBS serum with $0.2 \%$ Triton $X-100$. In other experiments, neurons were fixed and permeabilized with $100 \%$ methanol at $-20^{\circ} \mathrm{C}$ for $5 \mathrm{~min}$ and subsequent steps were carried in PBS serum.

For double-labeling experiments, cells were fixed with paraformaldehyde, incubated with mab22 $\mathrm{Cl} 1$ as above, and then incubated with either monoclonal anti-clathrin (Boehringer) or polyclonal anti-MAP2 or anti-tau (gifts of Dr. A. Fellous) and diluted in PBS serum with (MAP2 and tau) or without (clathrin) $0.2 \%$ Triton X-100. Immunoreactivity was visualized using FITC- or TRITC-conjugated appropriate secondary antibodies (Amersham).

For immunocytochemistry on live cells mab22C11 was incubated for $60 \mathrm{~min}$ or $4 \mathrm{hr}$ on ice or at higher temperatures $\left(15^{\circ} \mathrm{C}\right.$ or $\left.37^{\circ} \mathrm{C}\right)$. In some of these experiments, permeabilization with $0.001 \%$ saponin in the culture medium for $20 \mathrm{~min}$ at room temperature was performed before incubation with the first antibody. The cells were then washed and fixed in $4 \%$ paraformaldehyde, and immunoreactivity revealed as described above.

Confocal laser microscopy. Confocal laser microscopy was performed on a Molecular Dynamics 1000 system using dedicated image software. For the comparison of fluorescence in different experimental conditions, the scanning intensity was first empirically determined so that the signal of the most intensely labeled cells was below saturation, and then these conditions were used for all subsequent cell scanning.
Quantification by confocal laser microscopy was obtained by scanning five fields ( $512 \times 512$ pixel image size) at the same intensity with 0.5 $\mu \mathrm{m}$ section increments. The most fluorescent section in each of the five series per condition was quantified. The same threshold of pixel amount corresponding to the background was removed and the number of pixels obtained was divided by the number of cells in the field.

Calcium ionophore treatment. Ionomycin or A23187 (to a final concentration of $10^{-6} \mathrm{M}$ ) was added to 3-5 DIV neurons for 2-4 min. To test the effects of calcium, the ionophores were also added to cells in calcium-free media. Treatment was stopped with paraformaldehyde (immunocytochemistry) or with PBS rinses (biochemical studies).

Cell cytoskeleton preparation. Detergent-soluble and -insoluble fractions of embryonic neurons were prepared according to Refolo et al. (1991). The cells were washed twice in PBS containing $\mathrm{Ca}^{2+}$ and $\mathrm{Mg}^{2+}$ and once in buffer A (10 mM PIPES pH 6.9, 5 mM EGTA, $5 \mathrm{~mm} \mathrm{MgCl}_{2}$, $2 \mathrm{M}$ glycerol, and protease inhibitors) and then incubated for $5 \mathrm{~min}$ at room temperature in buffer $\mathrm{A}$ with $0.25 \%$ Triton $\mathrm{X}-100$. Extracted proteins were centrifuged at room temperature $(15,000 \times \mathrm{g}, 15 \mathrm{~min})$ and the supernatant (detergent soluble fraction) was reserved. Unsolubilized cytoskeleton was scraped from the dishes in a minimal volume of buffer A, incubated on ice for $30 \mathrm{~min}$, and centrifuged at $10,000 \times$ $g\left(10 \mathrm{~min}, 4^{\circ} \mathrm{C}\right)$. The pellet was resuspended in $50 \mathrm{~mm}$ Tris- $\mathrm{HCl} \mathrm{pH}$ 7.4, $10 \mathrm{~mm}$ EGTA, $10 \mathrm{~mm}$ EDTA, $100 \mathrm{~mm} \mathrm{NaCl}, 1 \% \mathrm{SDS}$, and protease inhibitors, then triturated, boiled for $10 \mathrm{~min}$, and centrifuged at room temperature $(15,000 \times g, 15 \mathrm{~min})$. The pellet is referred to as the detergent-insoluble fraction.

Cell cytoskeleton polymerization was carried out according to Shelanski et al. (1972). Five days after plating, $200 \times 10^{6} \mathrm{embryonic}$ neurons were washed in PBS, harvested in buffer B (100 mM MES pH 6.75, 1 mм EGTA, $1 \mathrm{~mm} \mathrm{MgCl}_{2}$, and protease inhibitors) at $4^{\circ} \mathrm{C}$, lysed in icecold buffer $B$ containing $0.5 \%$ Triton $X-100$, homogenized, kept on ice for $30 \mathrm{~min}$, and centrifuged at $100,000 \times \mathrm{g}$ for $45 \mathrm{~min}$ at $4^{\circ} \mathrm{C}$. The supernatants were adjusted to $2 \mathrm{M}$ glycerol and $1 \mathrm{mM} \mathrm{GTP}$, incubated at $30^{\circ} \mathrm{C}$ for $30 \mathrm{~min}$, loaded onto a $1.5 \mathrm{M}$ sucrose layer, and centrifuged at $100,000 \times g$ for $2 \mathrm{hr} 30 \mathrm{~min}$ at $30^{\circ} \mathrm{C}$. Pelleted polymerized microtubules were resuspended in ice-cold buffer $B$, kept on ice for $30 \mathrm{~min}$, and centrifuged again $\left(100,000 \times \mathrm{g}, 4^{\circ} \mathrm{C} 45 \mathrm{~min}\right)$. The supernatant and pellet correspond to the cold-labile and cold-stable cytoskeleton fractions, respectively.

Brain cytoskeleton preparation. Typically, three to four adult rat brains were homogenized in ice-cold buffer B with or without $0.5 \%$ Triton $X-100$. Supernatants were adjusted to $2 \mathrm{M}$ glycerol and $1 \mathrm{~mm}$ GTP, incubated at $30^{\circ} \mathrm{C}$ for $30 \mathrm{~min}$ loaded onto a $1.5 \mathrm{M}$ sucrose layer, and centrifuged at $100,000 \times \mathrm{g}$ for $2 \mathrm{hr} 30 \mathrm{~min}$ at $30^{\circ} \mathrm{C}$.

Gel electrophoresis and immunoblotting. Equal amounts of protein $(50-70 \mu \mathrm{g})$ or fraction equivalents were separated on $7 \%$ SDS-polyacrylamide gels and transferred to Immobilon membranes (Millipore). Membranes were blocked for $2 \mathrm{hr}$ with $10 \%$ newborn calf serum in TBST (25 mM Tris- $\mathrm{HCl}$ pH 8.0,150 mM NaCl, 0.1\% Tween 20) and incubated overnight at $4^{\circ} \mathrm{C}$ with the primary antibodies diluted in TBST, $10 \%$ newborn calf serum (mab22 $\mathrm{Cl} 1,0.5 \mu \mathrm{g} / \mathrm{ml}$; anti-C-terminal, 1:2000; anti-NCAM from Sigma, 1:1000), and immunoreactivity was revealed with an alkaline phosphatase-conjugated secondary antibody (Southern Biotechnology Associates) diluted 1:500 in TBST-newborn calf serum. In some experiments, relative quantities of detected proteins were estimated by scanning densitometry.

\section{Results}

Neurons in culture express only full-length transmembrane $A P P$

Our primary embryonic neuron culture system results in cell populations with $95-99 \%$ neurons, and in cultures from E15 or E16 cortex, neuronal differentiation starts immediately, yielding cells with distinct axons and dendrites as early as 2-3 d in vitro. However, it should be noted that these conditions do not permit the formation of synaptic contacts.

The monoclonal antibody $22 \mathrm{C} 11$ (mab22 $\mathrm{C} 11$ ) recognizes an epitope in the N-terminal part of APP (Weidemann et al., 1989; Martin et al., 1991; Hilbich et al., 1993) and reveals a prominent protein band at $105 \mathrm{kDa}$ on Western blots containing extracts from cultured neurons $5 \mathrm{~d}$ in vitro (Fig. $1 A$, lane 2), which likely 
A

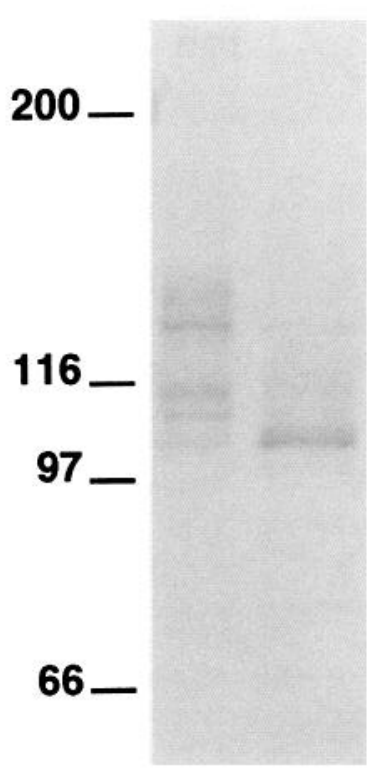

12
B

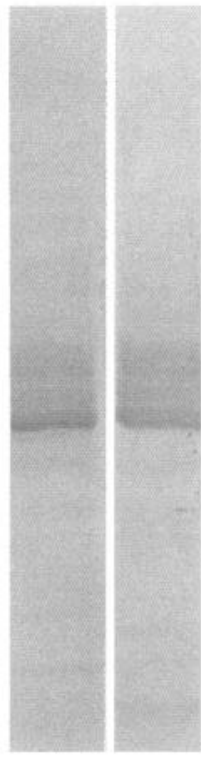

1

2

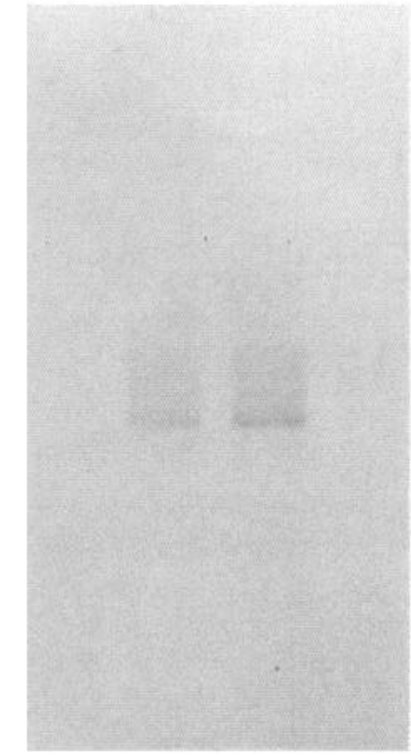

$\begin{array}{llll}1 & 2 & 3 & 4\end{array}$

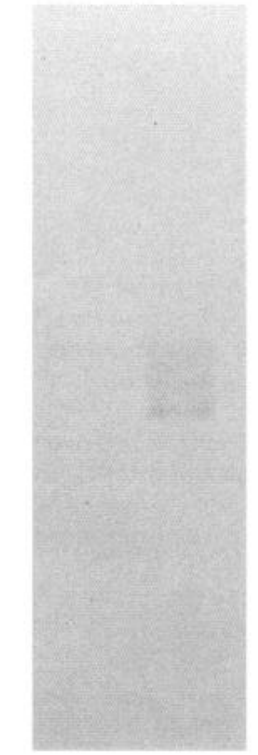

12

Figure 1. Immunoblot analysis of APP in neuronal extracts $(A)$. Mab22C11, which recognizes an epitope in the N-terminal region of APP, visualizes several APP isoforms in total extracts $\left(10^{6}\right.$ cells) from primary astrocyte (lane 1$)$ and embryonic cortical neuron (lane 2$)$ cultures. $B$, In extracts of cortical neuron cultures $\left(2 \times 10^{6}\right.$ cells) $5 \mathrm{DIV}$, the $\mathrm{N}$-terminal-specific (lane 1$)$ and C-terminal-specific (lane 2) antibodies recognize the same pattern of APP proteins. C, Partial subcellular fractionation of cultured cortical neurons examined with mab22C11 shows that APP is absent from the cytosolic fraction (lane 1), and present in the membrane-enriched fraction (lane 2). When the extraction is performed in the presence of $0.5 \%$ Triton X-100, APP is solubilized from the membrane and mab22 111 reveals the protein in the high-speed supernatant (lane 3), while little or no signal is present in the residual pellet (lane 4). D, The calcium ionophore ionomycin has no effect on the partitioning of APP between the membrane-enriched fraction (lane 2) and the cytosolic fraction (lane 1). In $C$ and $D$, each lane contains the fraction equivalent of 1.5 $\times 10^{6}$ cells.

corresponds to the APP695 isoform. Minor quantities of other proteins migrating with apparent molecular weights ranging from 108 to $120 \mathrm{kDa}$ can also be detected, which may represent posttranslationally modified forms of APP 695 or proteins derived from APP 751 and APP 770. These latter isoforms, which are prominent in astrocytes (Fig. 1, lane 1; Haass et al., 1991), might be due to the few astrocytes (1-5\% of the cells) present in the cultures. In neurons, none of the immunoreactive bands corresponded to KPI-containing isoforms, as we verified by polymerase chain reaction the absence of transcripts coding for the KPI domain (not shown). Finally, we found no evidence for a soluble form of APP in the conditioned medium from cultures of embryonic cortical neurons (not shown).

In total extracts from cultured neurons (5 DIV), the same pattern of proteins is recognized by antibodies specific for the $\mathrm{C}$-terminal and for the N-terminal of APP, indicating that only full-length transmembrane proteins are present in primary cortical neurons in vitro (Fig. $1 B$, lanes 1,2 ). This is confirmed by partial subcellular fractionation of neuronal cultures showing that while APP is not readily detected in the cytosolic fraction, it is present in the membrane-containing fraction (Fig. $1 C$, lanes $1,2)$. Treatment of the particulate fraction with $0.1 \mathrm{M}$ sodium carbonate, $\mathrm{pH} 11.05$, does not release APP, indicating that APP in the particulate fraction is tightly associated with the membrane. Furthermore, Triton X-100 solubilizes cellular membranes and results in the quantitative release (over $90 \%$ ) of the full-length isoforms of APP (Fig. $1 C$, lanes 3,4). Thus, all of the full-length APP detected with the two different antibodies corresponds to transmembrane isoforms.

\section{Transmembrane APP is not uniformly distributed}

We used immunostaining of neuronal cultures at 5 DIV to examine the localization of APP. Immunostaining of nonfixed living neurons with mab22 $\mathrm{C} 11$ results in no specific signal (Fig. $2 A, B)$, indicating that few epitopes are accessible at the surface of living cells. This absence of staining is not due to a nonimmunoreactive conformation of the epitope on live cells since permeabilizing live cells with $0.001 \%$ saponin before incubation with the mab22C11 results in clear APP immunoreactivity (Fig. $2 C$ ). The absence of APP at the neuronal surface is confirmed by experiments in which cell surface proteins are biotinylated, extracted, and purified on avidin-agarose. Figure $2 D$ shows that whereas the neural cell adhesion molecule (NCAM) is present in both intracellular (upper lane 1) and extracellular membrane (upper lane 2) fractions, APP cannot be detected in the fraction of surface proteins retained by the avidin-agarose (lower lane 2) and is present only in the nonretained fraction (lower lane 1).

Fixation of the cells in $4 \%$ paraformaldehyde prior to immunostaining reveals the presence of APP in $39.9 \pm 4.2 \%$ (mean \pm SEM, $n=3$ separate experiments) of the cells. In these conditions, APP immunoreactivity is observed in cell bodies and/ or neurites, and has a vesicular-like aspect with multiple fine fluorescent puncta. When APP is present in neurites it is not 

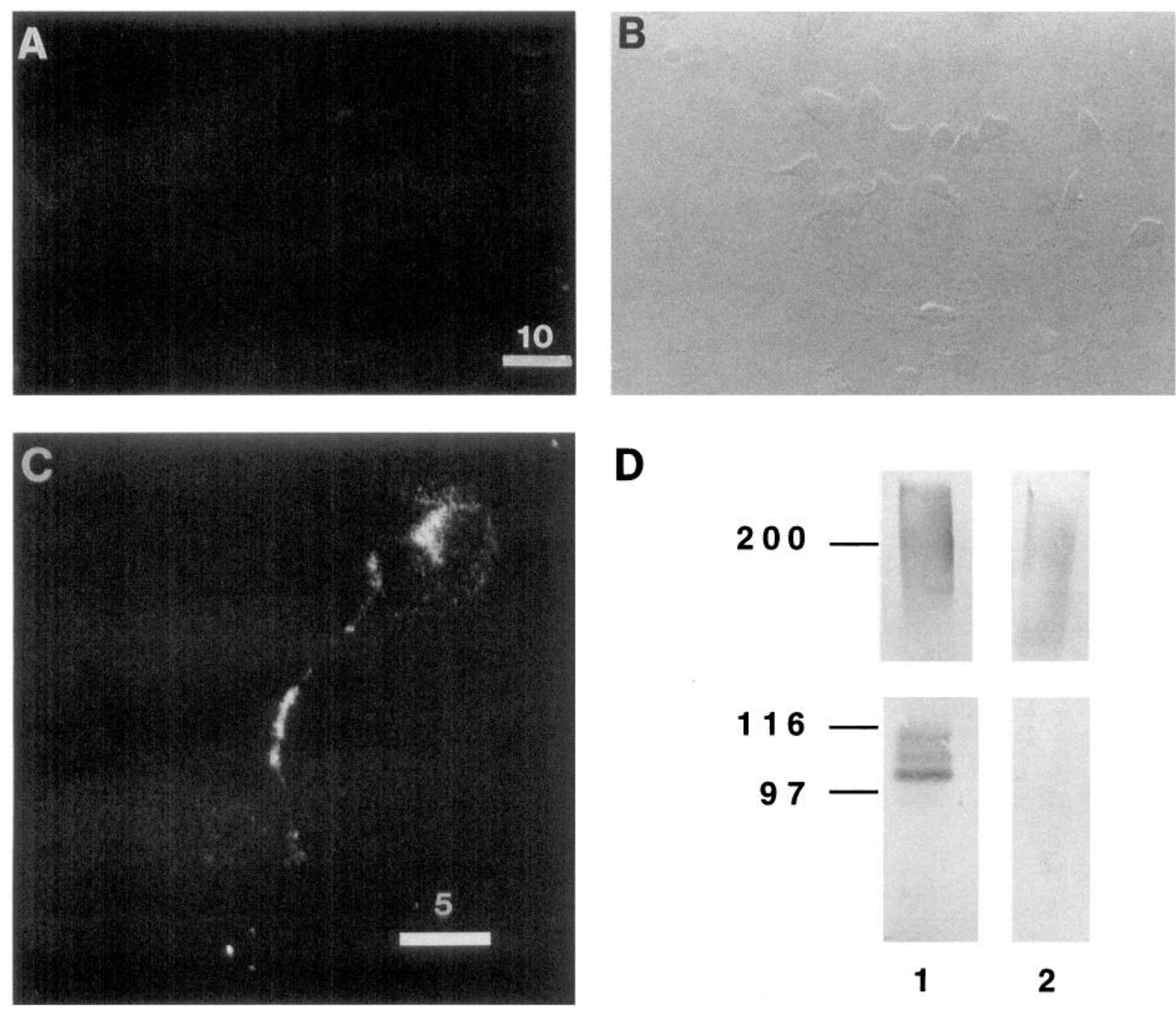

Figure 2. APP is not expressed at the surface of living embryonic cells. APP immunofluorescence is not detected on nonfixed cells $(A)$, while the same field viewed with phase contrast shows a number of viable neurons $(B)$. $C$, Confocal section of a neuron illustrating that after permeabilization with saponin at $0.001 \%$ for $20 \mathrm{~min}$, APP can be detected in the cell body and some neurites of living nonfixed neurons using mab22C11. $D$, After surface biotinylation of neurons in culture, proteins present intracellularly are not retained by avidin-agarose (lane 1), while biotinylated cell surface proteins are retained by avidin-agarose (lane 2). In contrast with NCAM, which is present both intracellularly and on the surface of neurons (respectively, upper portions of lanes 1 and 2), APP is only intracellular (lower portion of lane 1). The large spreading of NCAM immunoreactivity is due to the high levels of polysialylated NCAM isoforms in embryonic neurons.

uniformly distributed and the more intensely labeled neurites are long and thin with a constant diameter, three morphological characteristics reminiscent of axons. To investigate a possible enriched axonal localization of the staining, we performed double-labeling experiments using antibodies against APP and tau or MAP2 (Fig. 3), two cytoskeletal proteins enriched in the axonal and dendritic compartments, respectively (Kosik and Finch, 1987). Cells were fixed in $4 \%$ paraformaldehyde, incubated with mab22 11 , and permeabilized with Triton X-100 before incubating with anti-tau or anti-MAP2 antibodies. APP immunofluorescence is observed in neurites containing the axonal protein tau (Fig. $3 A-D$ ), and is only weakly present in neurites strongly immunoreactive for MAP2 (Fig. $3 E, F$ ), confirming that, with paraformaldehyde fixation, APP is primarily detected in the axon. We also observed that APP is not in all axons and is not uniformly distributed. Indeed, stretches of brightly labeled neurites interrupted by APP-negative regions are common (Fig. 3C,D).
We observed a marked difference in APP immunostaining when cells are permeabilized with Triton X-100 or with methanol before being exposed to mab22C11. While in the absence of detergent, cultures contain a high percentage (about $60 \%$ ) of nonimmunoreactive neurons, in Triton X-100-or in methanolpermeabilized cultures, $100 \%(n=5)$ of the cells become immunofluorescent (Fig. 4A,B). In addition, APP is widely and uniformly distributed in the neurons and is detected in all cellular compartments, that is, cell bodies, axons, and dendrites (Fig. $4 C, D$ ). No difference in the intensity of labeling can be observed between the different neurites. The addition of Triton $\mathrm{X}-100$ or of methanol after fixation does not modify the punctuate aspect of the labeling (Fig. 4C,D), making it rather unlikely that the change in its distribution can be attributed to detergentinduced diffusion of the antigen after fixation.

These differences in the intensity and distribution between cells treated with or without Triton X-100 suggest the existence of at least two pools of APP, a wide-spread pool accessible after 

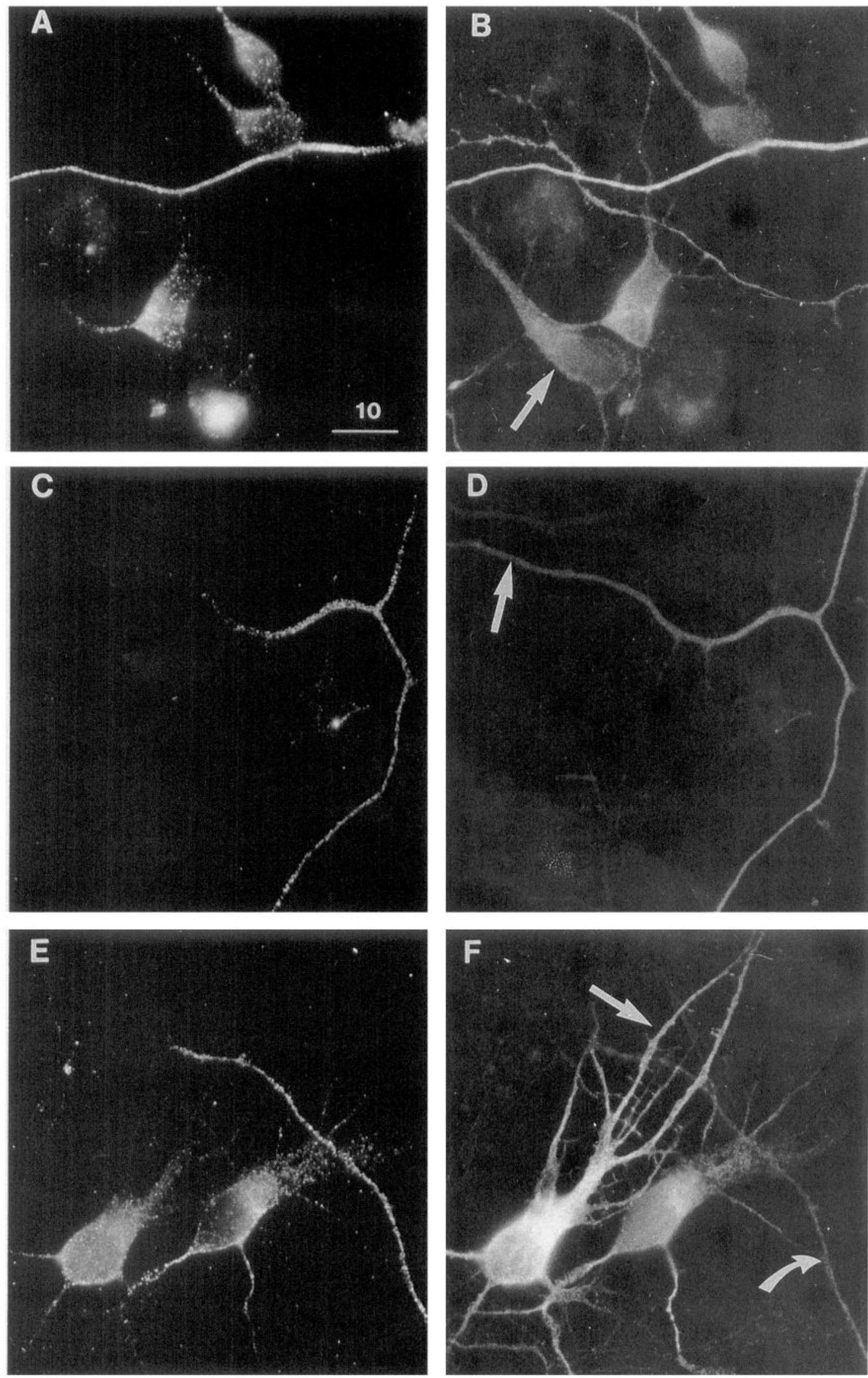
detergent permeabilization and a restricted pool mainly present in axons and cell bodies and virtually absent from the dendrites. The pattern of immunostaining, the absence of detectable extracellular APP, and the accessibility of the "axonal" pool after mild permeabilization suggest that it may reside with vesicular structures near the cell surface or be in poorly accessible membrane invaginations.

\section{Calcium entry changes APP distribution}

We next examined whether the axonal/somatic APP could be modified by physiological conditions. Since calcium entry is associated with several physiological events, including neurite elongation, and can lead to vesicle fusion and exocytosis, we examined the effect of two different calcium ionophores on the distribution of APP. In the absence of ionophore, or in the presence of ionophore but in the absence of calcium, only a fraction (approximately 40\%) of the cells fixed with $4 \%$ paraformaldehyde alone can be immunostained with the mab22C11 antibody (Fig. $5 A, B$ ). Two to five minutes after the addition of either ionomycin or A23187, APP is detected in virtually $100 \%$ of the cells fixed with $4 \%$ paraformaldehyde alone (Fig. $5 C, D$ ). Double-immunostaining experiments demonstrated that APP observed in neurites after calcium ionophore treatment is still primarily localized in cell bodies and axons. The distribution of APP within the ionophore-treated cells is thus similar to that observed in control conditions. In contrast, the intensity of the labeling is much stronger, as illustrated in Figure $5 A-D$ and quantified in Figure $5 E$.

As illustrated in the serial sections of Figure $6 A$, confocal microscopy also suggests that the punctuate APP immunoreactivity is close to the plasma membrane in both axons and cell bodies. Despite this distribution, no specific signal could be discerned on nonfixed, ionophore-treated living cells or in the culture medium. The absence of surface APP in ionophoretreated cells was confirmed by surface biotinylation experiments (not shown) identical to those of Figure 2. To investigate the nature of the vesicles with which APP is associated following calcium entry, we performed double-immunostaining experiments with anti-APP and anti-clathrin antibodies. Figure $6 B-$ $D$ illustrates that although some colocalization is obvious, several regions of axons and cell bodies are stained only with the anti-APP antibody, thus suggesting that a pool of non-clathrincoated vesicles contain the amyloid precursor. The nature of this pool is presently under study.

Western blot analysis showed that ionomycin does not increase the amounts of APP present in the cells, does not modify the patterns of migration on polyacrylamide gels, and does not increase significantly the amount of soluble APP (Fig. 1D). Thus, calcium influx has little effect on the synthesis and processing of APP or on its association with membranes. Nevertheless, at the whole-cell level, calcium entry greatly augments the number
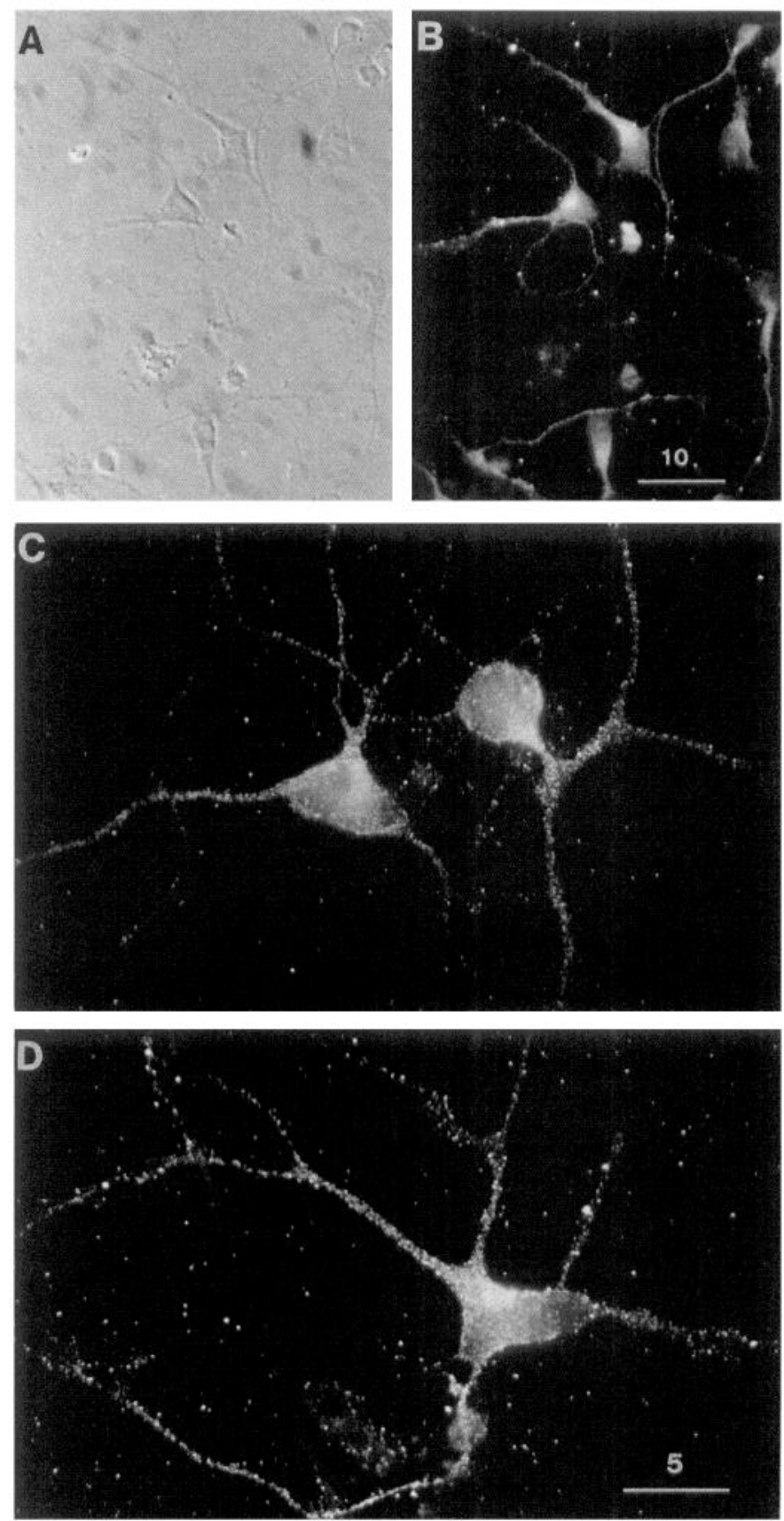

Figure 4. APP immunoreactivity in methanol- or Triton X-100-permeabilized neurons. Methanol fixation $\left(5 \mathrm{~min}\right.$ at $-20^{\circ} \mathrm{C}$, after paraformaldehyde treatment) demonstrates that APP immunofluorescence $(B)$ is visible in all neurites and cell bodies seen under phase contrast $(A)$. $C$ and $D$, High magnification of neurons after paraformaldehyde fixation and Triton X-100 permeabilization shows that APP immunoreactivity retains its punctuated appearance and is in all neurites.

Figure 3. APP localization in cultured embryonic neurons after fixation with $4 \%$ paraformaldehyde. APP $(A$ and $C)$ and tau $(B$ and $D)$ double immunostaining shows that APP is primarily present in some cell bodies and tau-positive neurites. $B$ was overexposed to allow the visualization of cells (arrow) not labeled with the APP antibody in $A$. A small axon with no APP immunoreactivity is also visible. When present, APP is not distributed on the entire length of the axon, as shown in $C$. The arrow in $D$ indicates a region of the axon labeled with tau antibody that does not show APP immunoreactivity $(C)$. APP $(E)$ and MAP2 $(F)$ double immunostaining reveals that APP is not found in the major dendrites identified by their tapering shapes and by their high MAP2 immunoreactivity (straight arrow, $F$ ). $F$ was overexposed to illustrate details. The visualization of the axon (curved arrow) is due to overexposure. It should also be noted that some staining can be attributed to the presence of small amounts of MAP2 in immature axons (Higgins et al., 1988). 

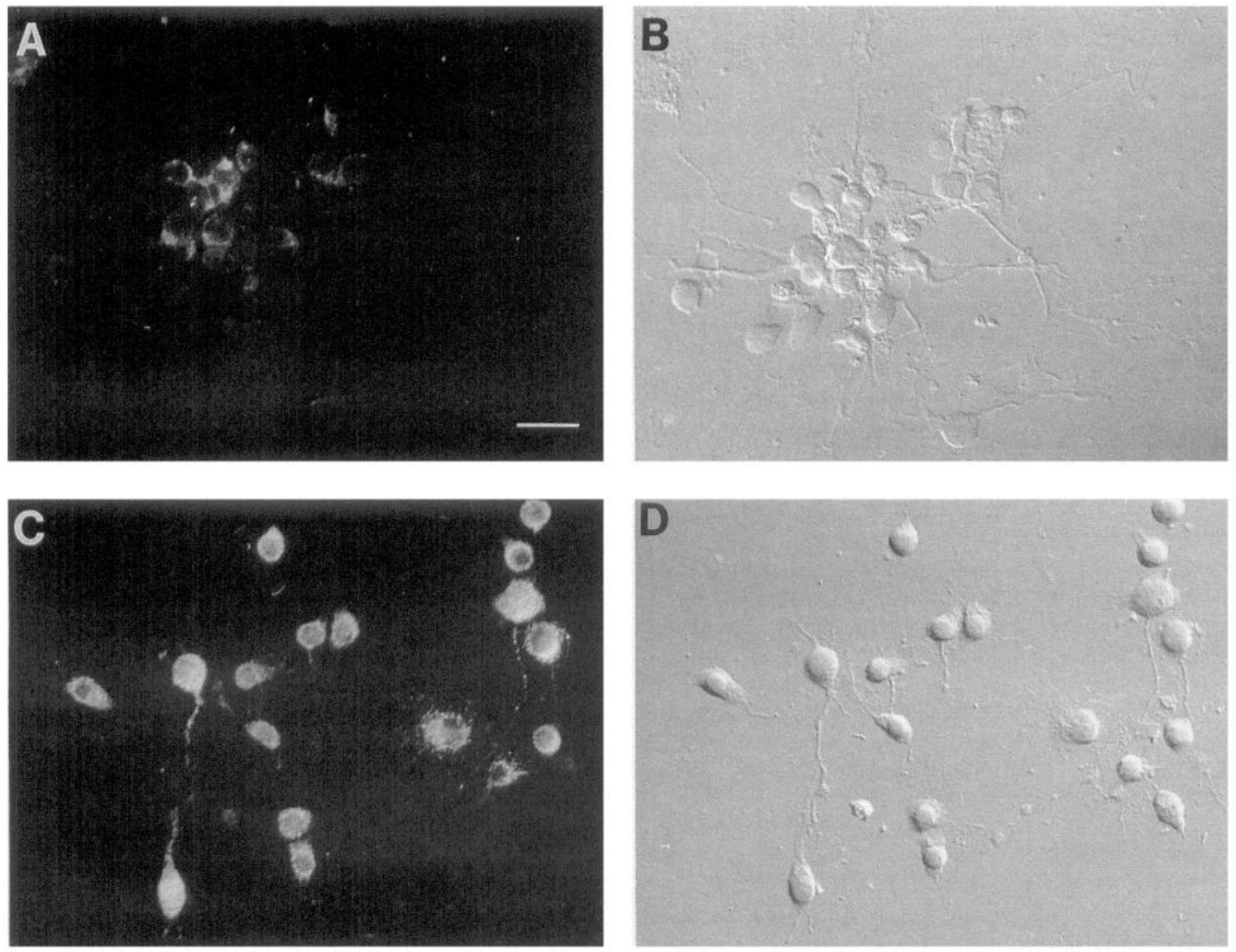

E

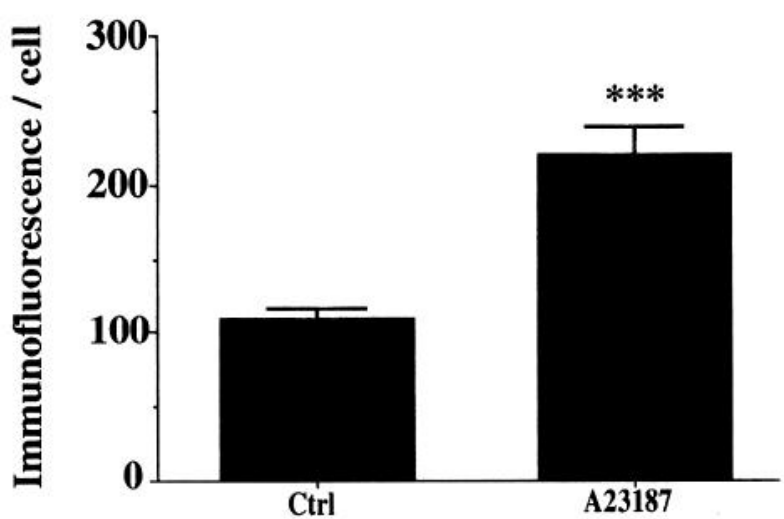

Figure 5. APP immunoreactivity after calcium ionophore treatment. Neurons 3 DIV were treated for 2 min without $(A$ and $B)$ or with $(C$ and $D) 10^{-6} \mathrm{M}$ ionophore A23187 and then APP was revealed with mab22C11. A23187 $(C$ and $D)$ greatly increased APP immunoreactivity compared to control neuronal cultures $(A$ and $B)$. Quantification of confocal microscopy shows a significantly enhanced staining per cell after ionophore treatment $(E ; p<0.001$, Student's $t$ test).

of immunoreactive neurons after paraformaldehyde fixation. It also markedly increases the intensity of this labeling in cell bodies and axons, suggesting an effect on the accessibility of the protein. The mode of action of calcium could be by modifying the epitope and making it more immunoreactive. It is also possible that high intracellular calcium mimics neuronal activity, promoting the translocation toward the cell surface of APPcontaining vesicles associated with the axonal cytoskeleton. 
Association of APP with the neuronal cytoskeleton

To test the association of APP with the cytoskeleton, we extracted E16 cortical ncurons (5 DIV) using Triton X-100 in conditions that preserve the structural integrity of major cytoskeletal elements (Refolo et al., 1991). We verified that in these conditions, synaptophysin and neurofilament-M are enriched in the soluble and insoluble fractions, respectively (not shown). APP is found in both the detergent-soluble and detergent-insoluble fractions (Fig. 7 $A$, lanes 1,2 ). The former contains truly soluble proteins as well as membrane proteins solubilized by Triton X-100, while the latter contains cytoskeletal elements and tightly associated proteins. The amounts of the precursor protein and the qualitative pattern of APP isoforms are similar in the two fractions.

This led us to investigate a possible direct association of APP with cytoskeletal elements in microtubule polymerization experiments. We first harvested cells under conditions that depolymerize the cytoskeleton and then exposed the samples to Triton X-100 to liberate APP from the membranes, since only transmembrane forms of APP are present in our cultures. Then the samples were placed in conditions to polymerize microtubules and the polymerized cytoskeleton was isolated by highspeed centrifugation. After cold-induced depolymerization the samples were centrifuged again at high speed to separate coldlabile and cold-stable cytoskeleton fractions. We then tested for the presence of APP in the different fractions and found the protein associated with the cold-stable cytoskeleton (Fig. $7 \mathrm{C}$, lanes 1-3).

\section{The C-terminus is necessary for APP association with the cytoskeleton}

One obvious possibility is that the association of APP with the cytoskeleton is mediated by its C-terminal region that, under physiological conditions, is oriented toward the cytoplasmic compartment. However, since Triton X-100 disrupts the membrane and liberates APP, association with the cytoskeleton could also occur via an $\mathrm{N}$-terminal region. In fact, the $\mathrm{N}$-terminus of APP contains a long stretch of acidic amino acids (residues 229260 , according to Shivers et al., 1988) that bears remarkable homology to an acidic sequence in tubulin. This acidic tubulin region is a known binding site for the basic repeats of the microtubule-associated protein tau, thus raising the possibility that APP may interact with an MAP and subsequently with tubulin through its $\mathrm{N}$-terminus.

To test directly if cytoskeleton-APP interactions could be mediated by the acidic region, we extracted neuronal cultures in conditions preserving polymerized microtubules in the absence or presence of the peptide (AEEEEVAEVEEEEADDDEDDEDGD) corresponding to the major part of this acidic APP region. As shown in Figure $7 B$, the presence of the peptide at concentrations $2.5 \times 10^{-6} \mathrm{M}$ or $2.5 \times 10^{-5} \mathrm{M}$ does not alter the partitioning of APP between the detergent-insoluble and-soluble cytoskeleton fractions, suggesting that the APP N-terminal acidic sequence alone does not mediate the association between APP and the cytoskeleton. Since the configuration of the peptide may not be ideal for competing with native APP, we further examined if the N-terminal portion of APP is sufficient for cytoskeleton association. We took advantage of the presence of secreted APP forms lacking the C-terminal region in the adult brain (Palmert et al., 1989). Adult rat brains were homogenized in the absence of Triton X-100 and the membranous and cy- tosolic fractions were separated by high-speed centrifugation. Western blots using mab22Cll and the C-terminal-specific antibody demonstrate that the cytosolic fractions contain primarily the N-terminal secreted region of APP (Fig. $8 A, B$ ), and that this N-terminal region of APP does not associate with the coldlabile or with the cold-stable polymerized cytoskeleton fractions (Fig. $8 C$ ). The addition of Triton X-100 to the secreted N-terminal form does not provoke an association with the polymerized cytoskeleton (not shown).

Finally, adult rat brains were homogenized in the presence of Triton X-100 to solubilize all APP isoforms and to examine if they are able to associate with the polymerized cytoskeleton. The different fractions were analyzed with the antibodies recognizing the APP $\mathrm{N}$ - and C-terminals. In Figure $8, D$ and $E$ show that, in contrast to isoforms lacking the C-terminus, the transmembrane isoforms recognized by the two antibodies strongly associate with the cold-stable polymerized cytoskeleton. Thus, in adult brain as in embryonic neurons, only transmembrane APP forms containing the C-terminal associate with the cytoskeleton.

\section{Discussion}

We found that cultures of cortical embryonic neurons contain only full-length transmembrane forms of APP. The virtual absence of cleaved and secreted forms of APP is consistent with recent results obtained with hippocampal cells (Hung et al., 1992). In addition, we could not detect the protein on the surface of living neurons, and this is similar to results using other brain cell types in primary culture (Haass et al., 1991). Paraformaldehyde fixation without further permeabilization revealed a striking APP immunoreactivity close to the cell surface that, under these conditions, is present in the cell body and axon but virtually absent from dendrites of polarized neurons. The protein seems localized near the plasma membrane, perhaps within vesicles or invaginations at the surface. Thus, without fixation, APP would be inaccessible from the exterior of cells, which could explain the absence of specific immunoreactivity on the surface of nonfixed, living cells.

Permeabilization with Triton X-100 after paraformaldehyde fixation revealed another pool of APP immunoreactivity that is distributed throughout the entire neuron, including both axons and dendrites. Since neurons in vitro contain only membrane-associated forms of APP, the protein visualized after permeabilization most likely represents APP on vesicles at a distance from the membrane. This APP may be associated with vesicles that are rapidly transported in axons (Koo et al., 1990; Ferreira et al., 1993; Moya et al., 1994) or associated with microtubules as seen in dendrites (Schubert et al., 1991). The intense labeling seen in the cell body may correspond to the different compartments where APP has already been observed, including endoplasmic reticulum, Golgi, late endosomes, or lysosomes (Benowitz et al., 1989; Palacios et al., 1992; Ferreira et al., 1993).

Ionomycin and A23187 markedly increase APP immunofluorescence at the membrane of paraformaldehyde-fixed cells without modifying its axosomatic distribution. The changes in the intensity of immunoreactivity after treatment are calcium dependent and cannot be explained by an effect on precursor protein synthesis since neither the levels of APP nor the pattern of isoforms present on Western blots is noticcably altered by the ionophores. It is noteworthy that although APP immunoreactivity is greatly enhanced in paraformaldehyde-fixed cells after ionophore treatment, no APP can be visualized in cultures 

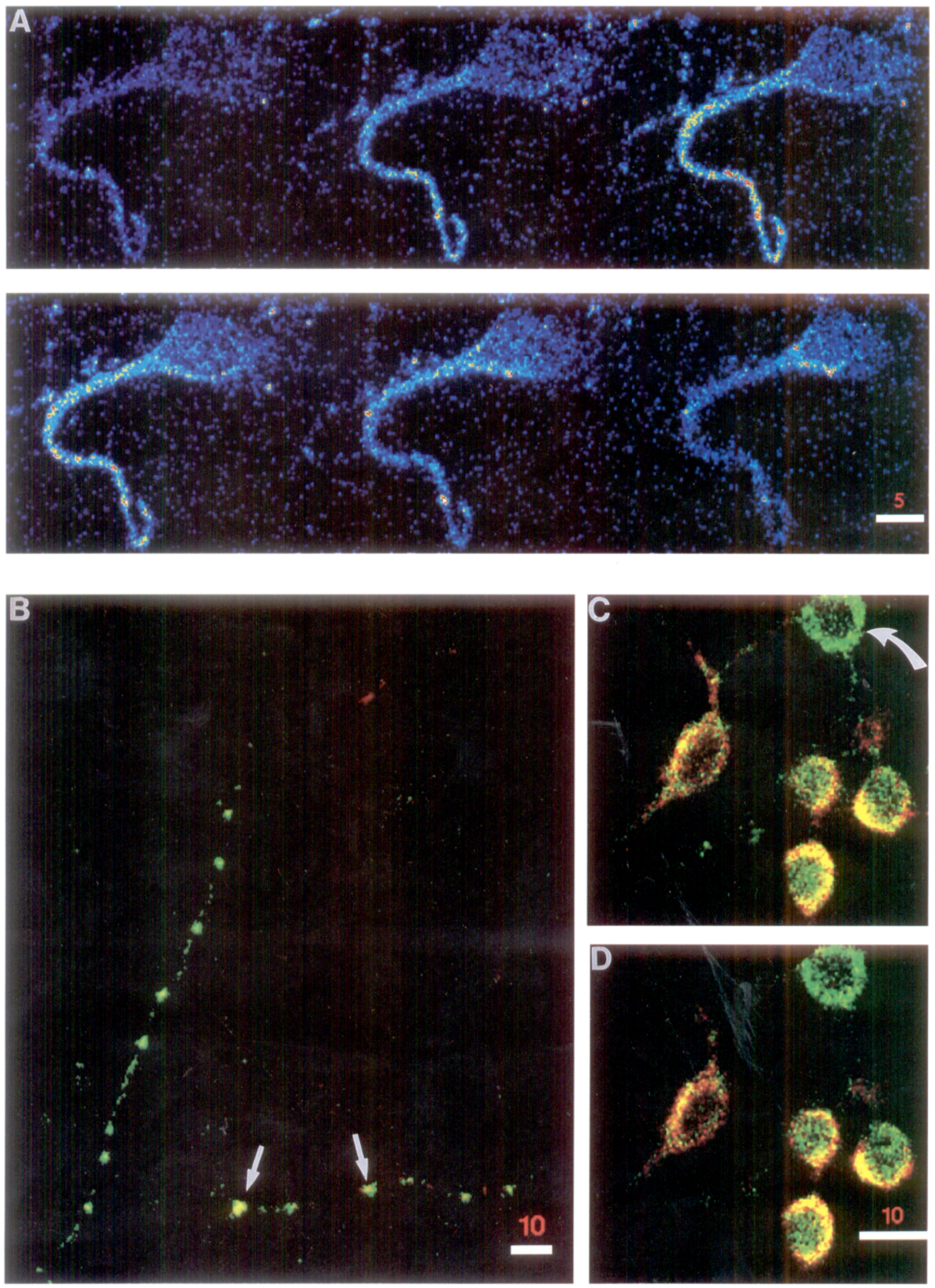
A

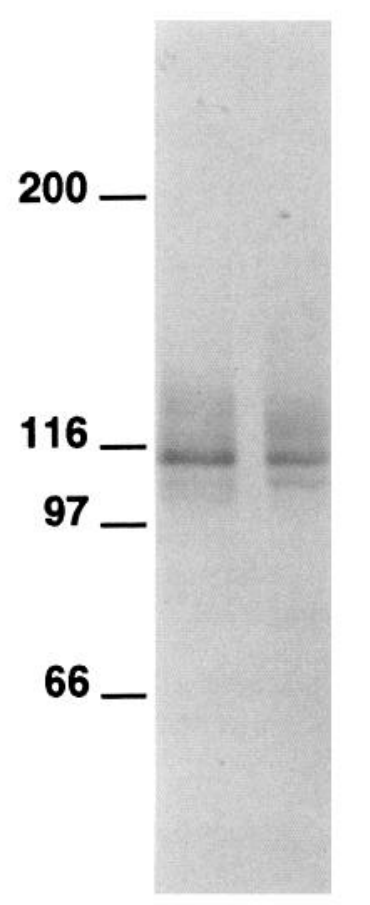

1
B

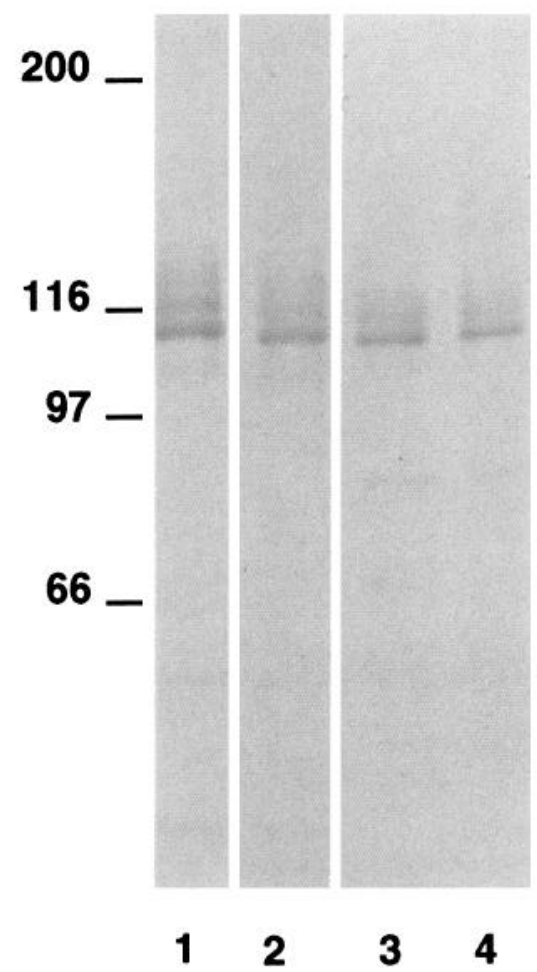

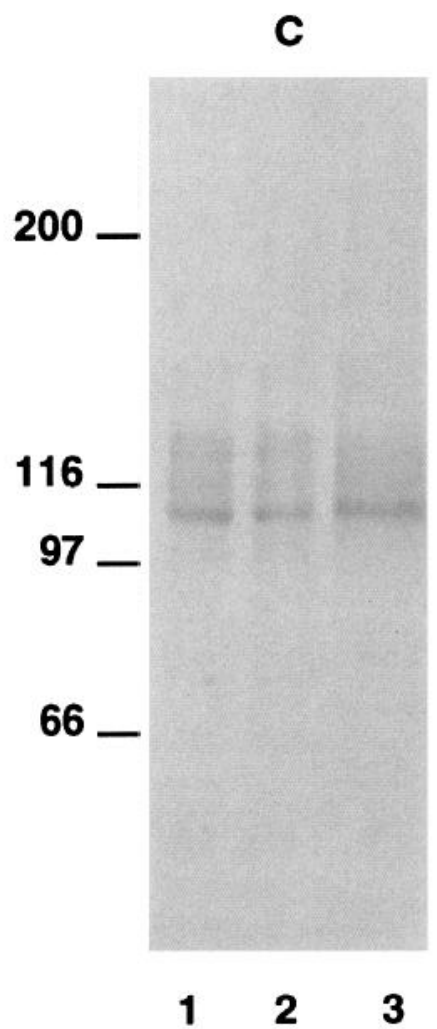

Figure 7. APP from embryonic neurons associates with the detergent-insoluble cytoskeleton. A, Cortical neurons 5 DIV were extracted in situ with $0.25 \%$ Triton X-100 in conditions that preserve the integrity of the cytoskeleton. Western blot analysis with mab22C11 shows similar levels of APP immunoreactivity in the detergent-soluble (lane 1) and detergent-insoluble (lane 2) fractions. Each lane contains the fraction equivalent of $1.5 \times 10^{6}$ cells. $B$, Cultured neurons were extracted with Triton X-100 in the presence (lanes 2 and 4 ) or absence (lanes 1 and 3 ) of $2 \times 10^{-5} \mathrm{M}$ acidic peptide. This peptide does not alter the pattern or the amount of APP in the detergent-soluble (lanes 1 and 2) or -insoluble (lanes 3 and 4 ) fractions. $C$, The high-speed supernatant of cells extracted in the presence of Triton X-100 contains APP as detected with mab22C11 (lane 1). When the microtubules in this fraction are polymerized, part of the APP does not associate with the polymerizable cytoskeleton and remains in the supernatant (lane 2). The detergent-insoluble, cytoskeleton-containing fraction also shows APP immunoreactivity (lane 3 ). Total of $50 \mu \mathrm{g}$ of protein were loaded onto each lane.

of living neurons, suggesting that even after calcium entry, APP is still not directly accessible at the cell surface. The absence of freely accessible protein at the cell surface correlates with the lack of measurable secretion of APP in these conditions and is consistent with the absence of ionophore-stimulated APP release in other cells capable of receptor-mediated APP secretion (Nitsch et al., 1992). Although the precise mechanism for the increased number of APP epitopes in the vicinity of the plasma membrane is still unknown, one possibility is that intracellular calcium triggers an accumulation of vesicles near the axonal membrane. However, the exposure of the protein at the surface and/or its secretion into the medium may require other steps, such as kinase activation or the onset of physiological activity (Caporaso et al., 1992a,b; Nitsch et al., 1993). It is also possible that in embryonic neurons the protein itself, in terms of posttranslational modifications (Weidemann et al., 1989; Oltersdorf et al., 1990) and/or the secretase, have not yet matured to a stage allowing detectable secretion.
Our results suggest the presence of transmembrane forms at or close to the axonal plasma membrane but not directly accessible on the exterior of neurons. One hypothesis is that APP at the plasma membrane may cycle rapidly in growing axons (Klier et al., 1990), and this would be consistent with the presence of APP in clathrin-coated vesicles in PC12 cells (Nordstedt et al., 1993). In fact, we are presently trying to identify the nature of the axonal APP-positive vesicles, and preliminary experiments strongly suggest that APP is present in different types of structures, including early endosomes, clathrin-coated vesicles, and vesicles enriched in glypiated molecules (C. Bouillot, A. Prochiantz, and B. Allinquant, unpublished observations). This latter finding suggests that APP might be present in caveolar structures known to be targeted to the apical compartment of cells in culture, the axon in the case of neurons (Dupree et al., 1993).

The stabilization of APP at the plasma membrane might involve homo- or heterophilic interactions with extracellular el-

\footnotetext{
Figure 6. Distribution of APP after ionomycin treatment. A series of confocal sections $(0.5 \mu \mathrm{m}$ increment $)$ shows that, after paraformaldehyde fixation alone, considerable APP is localized close to the membrane of the axon and cell body $(A)$. In double-immunofluorescence experiments, APP immunoreactivity was visualized with fluorescein (green) and clathrin immunoreactivity revealed with Texas red $(B-D)$. After confocal scanning with the appropriate excitations, the images were combined; the yellow indicates areas of APP/clathrin colocalization. Note that some colocalization is evident in axons (arrows in $B$ ) and cell bodies $(C$ and $D$ ). $C$ and $D$ are confocal sections separated by $1 \mu \mathrm{m}$ increment and show the same pattern of colocalization. In some cells, the APP/clathrin colocalization is sparse (arrow in $C$ ).
} 
A
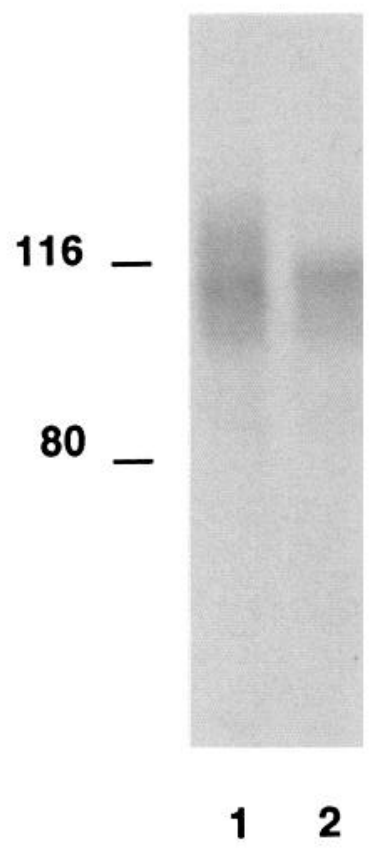

B

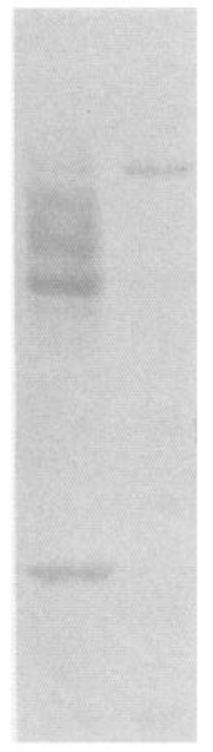

12
C

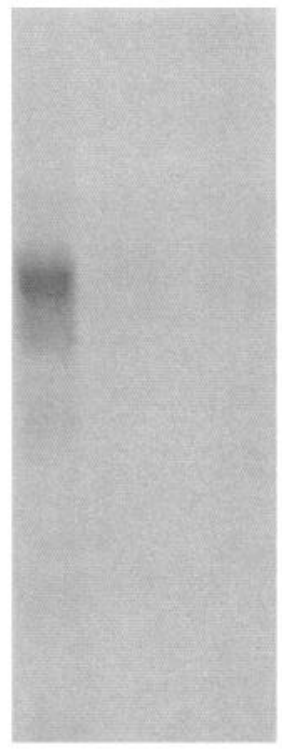

123
D
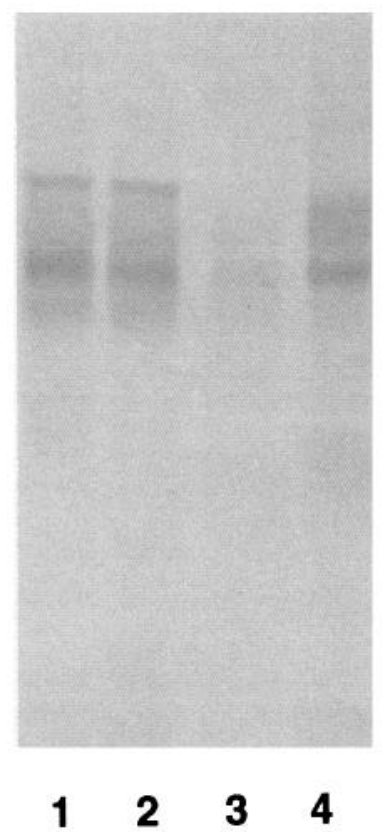

E

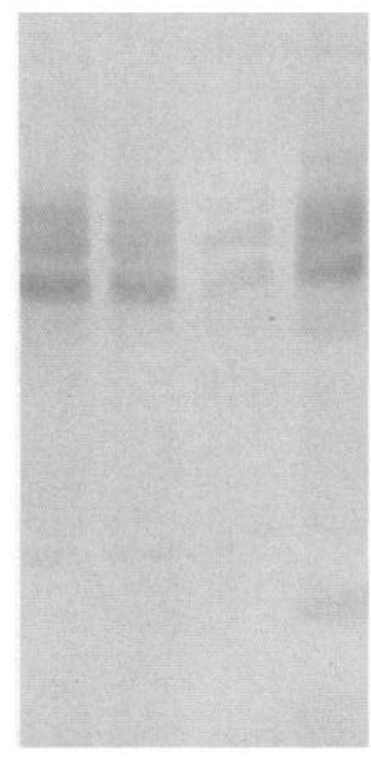

123

Figure 8. Polymerization of adult rat brain microtubules with or without Triton X-100. A, In the absence of detergent, the particulate (lane 1) and cytosolic (lane 2) fractions from adult rat brain contain APP detected with mab22C11. B, In the absence of detergent, the C-terminal-specific antibody shows numerous transmembrane forms of APP in the particulate fraction (lane 1) and few, if any, C-terminal-containing forms in the cytosolic fraction (lane 2). $C$, In the absence of detergent, polymerization of the microtubules in the cytosolic fraction shows little or no APP associated with either the cold-stable (lane 2) or cold-labile (lane 3) microtubules. All detectable APP remains in the supernatant of the microtubule pellet (lane 1$). D$ and $E$, When adult rat brain homogenates are extracted with Triton X-100, APP detected with mab22C11 $(D$, lanes $1-4)$ or with the C-terminal-specific antibody $(E$, lanes $1-4)$ is abundant in the initial high-speed supernatant $(D$ and $E$, lanes $I)$, the supernatant of the polymerized microtubules (lanes 2), and the detergent-insoluble cytoskeleton (lanes 4). Considerably less APP is detected in the cold-labile microtubule-containing fraction (lanes 3).

ements in order to participate in cell and substrate adhesion (Klier et al., 1990; Small et al., 1992). Such target elements could be present on postsynaptic sites, thus explaining the relative abundance of APP in the synapse (Schubert et al., 1991). It is interesting to note that in other studies we have observed an increased synthesis and rapid axonal transport of several forms of APP in the developing brain precisely at the time of target contact and synaptogenesis in vivo (Moya et al., 1994).

In this context, it is interesting that calcium influx had a striking effect on APP in axons, the domain of the neuron most likely to interact with target elements and be influenced by physiological stimuli. Although there is no direct evidence, we suggest that the calcium-dependent increase in APP may be due to a translocation of vesicles associated with the cytoskeleton along the axons, some of which may be destined for nerve terminals. As a first step in examining this possibility, we show that in neurons in culture, the association of APP with the polymerized cytoskeleton involves the C-terminal part of the protein.

Although the association of APP with the cytoskeleton has been reported before (Refolo et al., 1991), ours is the first demonstration involving neurons in primary culture. Moreover, to our knowledge, all previous studies used detergent extracts and thus could not determine whether the interaction was through the APP N-or C-terminus. This latter point is not trivial because the APP N-terminus contains an acidic sequence that is highly similar to a stretch of amino acids in tubulin, which is capable of interacting with several MAPs, including tau. Under normal physiologic conditions, interactions between the APP N-terminal and the cytoskeleton should not occur since the N-terminus is sequestered within vesicular structures or exposed at the neuronal surface. However, in nonphysiological conditions or in some pathologies, an induced accessibility of APP N-terminal regions could lead to catastrophic interactions between APP and cytoskeletal elements. In this regard, it is interesting to note that antibodies directed against the N-terminal of APP stain abnormal filaments in tangle-containing neurons (McGeer et al., 1992).

Our results strongly suggest that in the intact neuron, both in embryonic cells and in the adult brain, the interaction of APP with the cytoskeleton requires the presence of a C-terminal region, which is oriented in the cytoplasm and contains a site for phosphorylation (Gandy et al., 1988). This is in agreement both with the observation that in a glioma cell line (Refolo et al., 1991) the association of APP with the cytoskeleton is phosphorylation dependent, and with the finding that APP C-terminal fragments can form complexes with the microtubuleassociated protein tau (Caputo et al., 1992).

In conclusion, our data demonstrate that in neurons, a pool of APP highly enriched in the axon is located near the cell surface, while another is present in all compartments and less accessible to antibodies following mild fixation. We speculate that, at least in the axon, this latter pool is associated with the 
cytoskeleton and that upon calcium entry, this interaction is altered allowing APP-containing vesicles to accumulate under the plasma membrane or recycle very rapidly with the axonal membrane. However, in this model, APP stabilization at the surface and its significant release into the extracellular space may depend upon additional signals and/or further maturation.

\section{References}

Benowitz LI, Rodriguez W, Paskevitch P, Mufson EJ, Schenk D, Neve RL (1989) The amyloid precursor protein is concentrated in neuronal lysosomes in normal and Alzheimer disease subjects. Exp Neurol 106:237-250.

Breen KC, Bruce M, Anderton BH (1991) Beta amyloid precursor protein mediates neuronal cell-cell and cell-surface adhesion. $J$ Neurosci Res 28:90-100.

Caporaso GL, Gandy SE, Buxbaum JD, Greengard P (1992a) Chloroquine inhibits intracellular degradation but not secretion of $\mathrm{Alz}$ heimer $\beta /$ A4 amyloid precursor protein. Proc Natl Acad Sci USA 89: 2252-2256.

Caporaso GL, Gandy SE, Buxbaum JD, Ramabhadran TV, Greengard P (1992b) Protein phosphorylation regulates secretion of Alzheimer $\beta / A 4$ amyloid precursor protein. Proc Natl Acad Sci USA 89:30553059.

Caputo CB, Sygowski LA, Scott CW, Evangelista Sobel IR (1992) Role of tau in the polymerization of peptides from $\beta$-amyloid precursor protein. Brain Res 597:227-232.

Dupree P, Parton RG, Raposo G, Kurzchalia TV, Simons K (1993) Caveolae and sorting in the trans-Golgi network of epithelial cells. EMBO J 12:1597-1605.

Esch FS, Keim EC, Blacher RW, Culwell AR, Oltersdorf T, McClure D, Ward PJ (1990) Cleavage of amyloid $\beta$ peptide during constitutive processing of its precursor. Science 248:1 122-1124.

Estus S, Golde TE, Kunishita T, Blades D, Lowery D, Eisen M, Usiak M, Qu X, Tabira T, Greenberg BD, Younkin SG (1992) Potentially amyloidogenic, carboxyl-terminal derivatives of the amyloid protein precursor. Science 255:726-728.

Ferreira A, Caceres A, Kosik K (1993) Intraneuronal compartments of the amyloid precursor protein. J Neurosci 13:3112-3123.

Gandy S, Czernik AJ, Greengard P (1988) Phosphorylation of Alzheimer disease amyloid precursor peptide by protein kinase $C$ and $\mathrm{Ca}^{++} /$calmodulin-dependent protein kinase 11. Proc Natl Acad Sci USA 85:6218-6221.

Golde TE, Estus S, Younkin LH, Selkoe DJ, Younkin SG (1992) Processing of the amyloid protein precursor to potentially amyloidogenic derivatives. Science 255:728-730.

Haass C, Hung AY, Selkoe DJ (1991) Processing of $\beta$-amyloid precursor protein in microglia and astrocytes favors an internal localization over constitutive secretion. J Neurosci 11:3783-3793.

Haass C, Schlossmacher MG, Hung AY, Vigo-Pelfrey C, Mellon A, Ostaszewski BL, Lieberburg I, Koo EH, Schenk D, Teplow DB, Selkoe DJ (1992) Amyloid $\beta$-peptide is produced by cultured cells during normal metabolism. Nature 359:322-325.

Higgins D, Waxman A, Banker G (1988) The distribution of microtubule-associated protein 2 changes when dendritic growth is induced in rat sympathetic neurons in vitro. Neuroscience 24:583-592.

Hilbich C, Mönning U, Grund C, Masters CL, Beyreuther K (1993) Amyloid-like properties of peptides flanking the epitope of amyloid precursor protein-specific monoclonal antibody $22 \mathrm{Cll}$. J Biol Chem 268:26571-26577.

Hung AY, Koo EH, Haass C, Selkoe DJ (1992) Increased expression of $\beta$-amyloid precursor protein during neuronal differentiation is not accompanied by secretory cleavage. Proc Natl Acad Sci USA 89: 9439-9443.

Kang J, Lemaire HG, Unterbeck A, Salbaum JM, Masters CL, Grzeschik KH, Multhaup G, Beyreuther K, Müller-Hill B (1987) The precursor of Alzheimer's disease amyloid A4 protein resembles a cellsurface receptor. Nature 325:733-736.

Klier FG, Cole G, Stallcup W, Schubert D (1990) Amyloid $\beta$-protein precursor is associated with extracellular matrix. Brain Res 515:336342.

Koo EH, Sisodia SS, Archer DR, Martin LJ, Weidemann A, Beyreuther K, Fischer P, Masters CL, Price DL (1990) Precursor of amyloid protein in Alzheimer disease undergoes fast anterograde axonal transport. Proc Natl Acad Sci USA 87:1561-1565.

Kosik KS, Finch EA (1987) MAP2 and tau segregate into axonal and dendritic domains after the elaboration of morphologically distinct neurites: an immunocytochemical study of cultured rat cerebrum. $\mathbf{J}$ Neurosci 7:3142-3153.

Lafont F, Rouget M, Triller A, Prochiantz A, Rousselet A (1992) In vitro control of neuronal polarity by glycosaminoglycans. Development 114:17-29.

Martin LJ, Sisodia SS, Koo EH, Cork LC, Dellovade TL, Weidemann A, Beyreuther K, Masters C, Price DL (1991) Amyloid precursor protein in aged nonhuman primates. Proc Natl Acad Sci USA 88: 1461-1465.

McCarthy KD, de Vellis J (1980) Preparation of separate astroglial and oligodendroglial cell cultures from rat cerebral tissue. J Cell Biol 85:890-892.

McGeer PL, Akiyama H, Kawamata T, Yamada T, Walker DG, Ishii $T$ (1992) Immunohistochemical localization of beta-amyloid precursor protein sequences in Alzheimer and normal brain tissue by light and electron microscopy. J Neurosci Res 31:428-442.

Moya KI, Benowitz II, Schneider GE, Allinquant B (1994) The amyloid precursor protein is developmentally regulated and correlated with synaptogenesis. Dev Biol 161:597-603.

Nishimoto I, Okamoto T, Matsuura Y, Takahashi S, Okamoto T, Myramama Y, Ogata E (1993) Alzheimer amyloid protein precursor complexes with brain GTP-binding protein $G_{0}$. Nature 362:75-79.

Nitsch RM, Slack BE, Wurtman RJ, Growdon JH (1992) Release of Alzheimer amyloid precursor derivatives stimulated by activation of muscarinic acetylcholine receptors. Science 258:304-307.

Nitsch RM, Farber SA, Growdon JH, Wurtman RJ (1993) Release of amyloid $\beta$-protein precursor derivatives by electrical depolarization of rat hippocampal slices. Proc Natl Acad Sci USA 90:5191-5193.

Nordstedt C, Caporaso GL, Thyberg J, Gandy SE, Greengard P (1993) Identification of the Alzheimer $\beta / A 4$ amyloid precursor protein in clathrin-coated vesicles purified from PC12 cells. J Biol Chem 268 : 608-612.

Oltersdorf T, Ward PJ, Henrikson T, Beattie EC, Neve R, Lieberburg I, Fritz LC (1990) The Alzheimer amyloid precursor protcin: identification of a stable intermediate in the biosynthetic/degradative pathway. J Biol Chem 265:4492-4497.

Palacios G, Palacios JM, Mengod G, Frey P (1992) $\beta$-Amyloid precursor protein localization in the Golgi apparatus in neurons and oligodendrocytes. An immunocytochemical structural and ultrastructural study in normal and axotomized neurons. Mol Brain Res 15: 195-206.

Palmert MR, Podlisny MB, Witker DS, Olderstorf T, Younkin LH, Selkoe DJ, Younkin SG (1989) The $\beta$-amyloid protein precursor of Alzheimer disease has soluble derivatives found in human brain and cerebrospinal fluid. Proc Natl Acad Sci USA 86:6338-6342.

Refolo LM, Wittenberg IS, Friedrich VL Jr, Robakis NK (1991) The Alzheimer amyloid precursor is associated with the detergent-insoluble cytoskeleton. J Neurosci 11:3888-3897.

Schubert D, Jin LW, Saitoh T, Cole G (1989) The regulation of amyloid $\beta$ protein precursor secretion and its modulatory role in cell adhesion. Neuron 3:689-694.

Schubert W, Prior R, Weidemann A, Dircksen H, Multhaup G, Masters $\mathrm{CL}$, Beyreuther K (1991) Localization of Alzheimer $\beta$ A4 amyloid precursor protein at central and peripheral synaptic sites. Brain Res 563:184-194.

Selkoe DJ (1991) The molecular pathology of Alzheimer's disease. Neuron 6:487-498.

Seubert P, Vigo-Pelfrey C, Esch F, Lee M, Dovey H, Davis D, Sinha S, Schlossmacher M, Whaley J, Swindlehurst C, McCormack R, Wolfert R, Selkoe D, Lieberburg I, Schenk D (1992) Isolation and quantification of soluble Alzheimer's $\beta$-peptide from biological fiuids. $\mathrm{Na}$ ture 359:325-327.

Shelanski ML, Gaskin F, Cantor CR (1972) Microtubule assembly in the absence of added nucleotides. Proc Natl Acad Sci USA 70:765768 .

Shivers BD, Hilbich C, Multhaup G, Salbaum M, Beyreuther K, Seeburg PH (1988) Alzheimer's disease amyloidogenic glycoprotein: expression pattern in rat brain suggests a role in cell contact. ЕМВО J 7:1365-1370.

Sisodia SS (1992) $\beta$-Amyloid precursor protein cleavage by a membrane-bound protease. Proc Natl Acad Sci USA 89:6075-6079. 
Sisodia SS, Koo EH, Beyreuther K, Unterbecck A, Price DL (1990) Evidence that $\beta$-amyloid protein in Alzheimer's disease is not derived by normal processing. Science 248:492-495.

Small DH, Nurcombe V, Moir R, Michaelson S, Monard D, Beyreuther $\mathrm{K}$, Masters CL (1992) Association and release of the amyloid precursor of Alzheimer's disease from chick brain extracellular matrix. J Neurosci 12:4143-4150.
Weidemann A, König G, Bunke D, Fischer P, Salbaum JM, Masters CL, Beyreuther K (1989) Identification, biogenesis, and localization of precursors of Alzheimer's disease A4 amyloid protein. Cell 57: $115-126$ 